\section{Commentary: The Ross procedure: Just do it, or less, or a loss?}

\author{
Lars G. Svensson, MD, PhD
}

I confess that I have mixed views about the Ross procedure and could argue for or against both the pros and cons. Four decades of being exposed to the procedure have revealed to me that better options exist, especially for aortic valve regurgitation (AVR). Donald Ross, a South African who learned about homograft and allograft research at the University of Pretoria, later described the procedure of taking the pulmonary autograft and placing it into the aortic root, then replacing the removed pulmonary valve with a homograft.

Like most young tyros, I did many Ross procedures and never reoperated on any of my own patients. However, surgeons with much larger series, including Yacoub, Knott-Craig, Elkins, Starnes, Cosgrove, and David, began reporting concerning results, including greater-thanaverage mortality rates for AVR and long-term failures of the neoaortic valve, homograft, and aneurysm formation. ${ }^{1,2}$ We then began doing reimplantations of failed neoaortic valves (the original autograft) or Ross reversals, as well as AVR or more complex root procedures for failed valves or delayed root aneurysms after Ross procedures. These were often combined with pulmonary homograft replacements - in fact, we do more than primary Ross operations. ${ }^{3}$

In my opinion, we should not "just do it" for all stenosis or regurgitation patients simply because we can, irrespective of youth, and strong advocates, despite renewed enthusiasm, would agree. Rather, the procedure should be done less often, except for pediatric patients and young

From the Heart, Vascular, and Thoracic Institute, Cleveland Clinic, Cleveland, Ohio. Disclosures: The author reported no conflicts of interest.

The Journal policy requires editors and reviewers to disclose conflicts of interest and to decline handling or reviewing manuscripts for which they may have a conflict of interest. The editors and reviewers of this article have no conflicts of interest.

Received for publication July 29, 2021; revisions received July 29, 2021; accepted for publication July 30, 2021; available ahead of print Aug 4, 2021.

Address for reprints: Lars G. Svensson, MD, PhD, Department of Thoracic and Cardiovascular Surgery, Cleveland Clinic, 9500 Euclid Ave/J1-227, Cleveland, OH 44195 (E-mail: svenss1@ccf.org).

JTCVS Techniques 2021;10:394-5

2666-2507

Copyright (C 2021 The Author(s). Published by Elsevier Inc. on behalf of The American Association for Thoracic Surgery. This is an open access article under the CC BY-NC-ND license (http://creativecommons.org/licenses/by-nc-nd/4.0/).

https://doi.org/10.1016/j.xjtc.2021.07.029

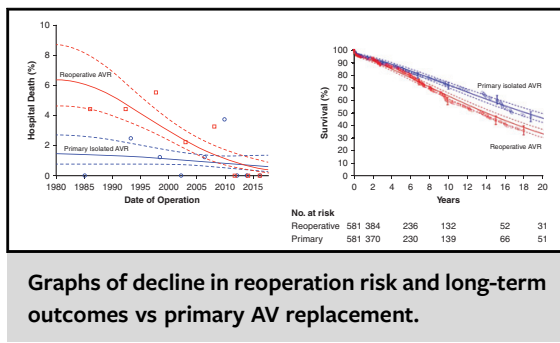

CENTRAL MESSAGE

Although ultimately up to the individual and surgeon, the Ross procedure should be used less often, and on a smaller, more exclusive group of patients.

adults up to 20 to 30 years old who have severe aortic valve stenosis, for whom it is not necessarily an increased risk of operative death, quality of life, or loss for them. I also do not believe the procedure is warranted for a patient with an ascending aortic aneurysm, based on the many reoperations I have seen for enlarged aortas, particularly with bicuspid valve pathology. Additionally, reducing the size of the annulus with some method, such as a suture (as I have tied around a Hegar dilator), may not be a good long-term solution. Using a bicuspid valve pulmonary autograft also should not be done. I have tested the pulmonary autograft under pressure before removing it for Ross procedures and noted - not infrequently - that it leaked while still in position on transesophageal intraoperative echocardiography; as a result, I did not use them. Thus, the pool of young candidate patients shrinks if one only considers those with stenosis and no aortic enlargement.

What about regurgitating aortic valves in young patients, who present a quandary when determining best treatments? The results $(<1 \%$ death) and control afforded by root reimplantation show excellent long-term results for young patients and tricuspid valves ( $>95 \% 10$-year freedom from reoperation), even if leaflet adjustments and repairs have to be done. ${ }^{4}$ What about the majority of young patients, who have regurgitation due to bicuspid valves? Given the risks and long-term consequences and newer options (which also appear in Table 1 of the article by Mazine and El-Hamamsy), I believe the Ross is a loss. If the root is small, my first choice is bicuspid valve repair with or without ascending aortic replacement $(0.25 \%$ operative mortality in 801 patients, no deaths in 130 reoperations after 

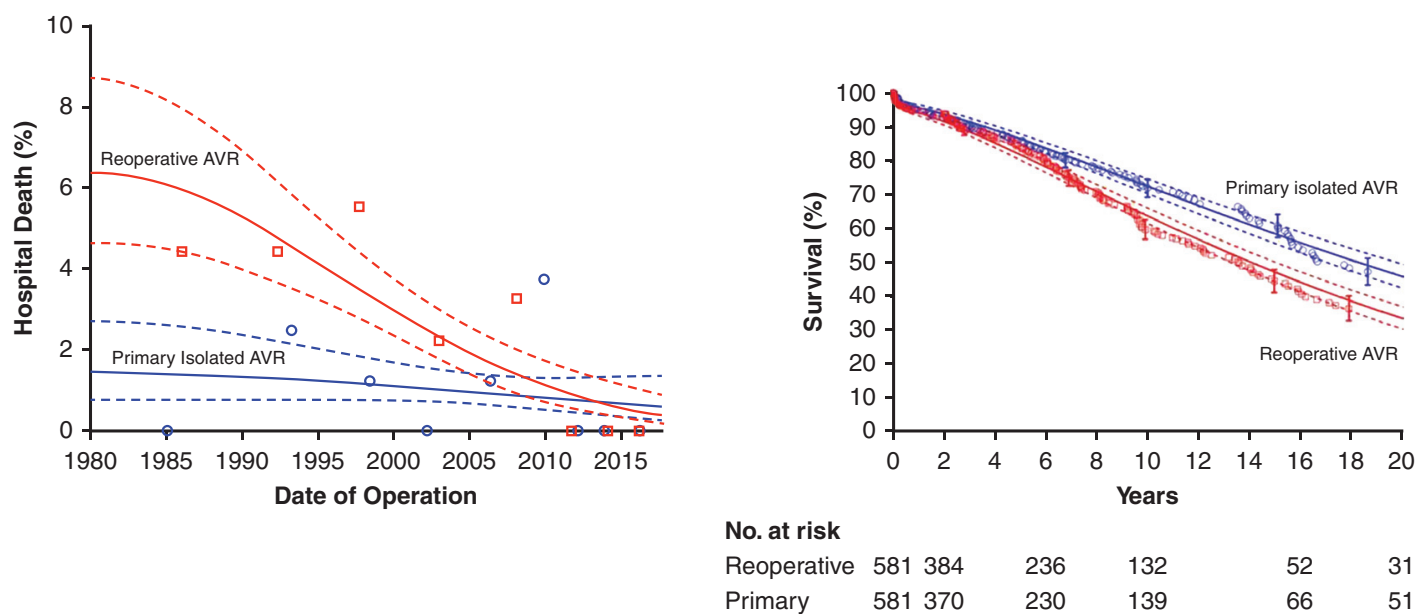

FIGURE 1. Graphs of decline in reoperation risk and long-term outcomes vs primary AV replacement.

repairs, and improving durability of repairs at 10 years). ${ }^{5}$ For enlarged aortic roots, I recommend remodeling or reimplantation with a large-diameter tube graft $(>34 \mathrm{~mm})$. If that is not an option, newer options with less risk for reoperation-such as an Ozaki repair (with results equivalent to pericardial valves) or biological valve replacement with a pericardial valve (which provides a good platform for transcatheter aortic valve replacement [TAVR] if needed)—can be considered. TAVR in Ross aortic valve positions, or stentless valve replacements, carries a greater risk of death, as with transcatheter pulmonary valve replacement for pulmonary homograft failure. ${ }^{6}$ Unfortunately, we now see failed TAVRs and transcatheter pulmonary valve replacements that need complex reoperations, including the replacement of both valves.

Starnes and colleagues ${ }^{7}$ have accumulated experience and excellent early results with Ross procedures, including in the pediatric population; for a growing child, a growing valve is an excellent option. Nevertheless, even with a tube graft wrapped around the autograft, failures do occur. Furthermore, the idea that a wrap at the annulus will stop long-term failure is unlikely to solve the problem as the authors suggest; discovering that in 10 to 20 years is too late. The solutions tried by others, including Cosgrove, who wrapped his autograft's annulus, still failed over time and required reoperations. Furthermore, in the adult population with regurgitation, newer options are better choices; even if they fail, the reoperation risks are negligible in comparison to a primary AVR (see Figure 1). ${ }^{8}$ The extra pump time and aortic crossclamp time, greater risk of death, right ventricular dysfunction, arrhythmias from damage to conal arteries, pacemakers, 2 valves at risk, and durability problems (as summarized in Table 1 of Kindzelski and colleagues' article) do not justify the Ross for aortic valve regurgitation in adults. ${ }^{8}$

The Ross procedure has its place, but that place is in a limited group of fewer patients. There are now better, safer, simpler, quicker, and more durable options for those with regurgitating aortic valves, especially with any aortic root enlargement. My final recommendation is that the patient should choose what they would prefer from the less-thanideal options based on a fully informed discussion with their surgeon over the pros and cons of each procedure; none, however, is a perfect option.

\section{References}

1. Svensson LG, Blackstone EH, Cosgrove DM. Surgical options in young adults with aortic valve disease. Curr Probl Cardiol. 2003;28:417-80.

2. Mazine A, El-Hamamsy I. Tailoring the Ross procedure for patients with aortic regurgitation. J Thorac Cardiovasc Surg Tech. 2021;10:383-9.

3. Pettersson GB, Subramanian S, Flynn M, Nowicki ER, Batizy LH, Svensson LG et al. Reoperations after the Ross procedure in adults: towards autograft-sparing/ Ross reversal. J Heart Valve Dis. 2011;20:425-32.

4. Mokashi SA, Rosinski BF, Desai MY, Griffin BP, Hammer DF, Kalahasti V, et al. Aortic root replacement with bicuspid valve reimplantation: are outcomes and valve durability comparable to those of tricuspid valve reimplantation? J Thorac Cardiovasc Surg. May 11, 2020 [Epub ahead of print].

5. Svensson LG, Al Kindi AH, Vivacqua A, Pettersson GB, Gillinov AM Mihaljevic T, et al. Long-term durability of bicuspid aortic valve repair. Ann Thorac Surg. 2014;97:1539-47; discussion 1548.

6. Kapadia S, Tuzcu EM, Svensson LG. Anatomy and flow characteristics of neosinus: important consideration for thrombosis of transcatheter aortic valves. Circulation. 2017;136:1610-2.

7. Starnes VA, Elsayed RS, Cohen RG, Olds AP, Bojko MM, Mack WJ, et al. Long term outcomes with the pulmonary autograft inclusion technique in adults with bicuspid aortic valves undergoing the Ross procedure. J Thorac Cardiovasc Surg. February 4, 2021 [Epub ahead of print].

8. Kindzelski BA, Bakaeen FG, Tong MZ, Roselli EE, Soltesz EG, Johnston DR, et al. Modern practice and outcomes of reoperative cardiac surgery. J Thorac Cardiovasc Surg. January 23, 2021 [Epub ahead of print]. 